\title{
COMPUTER AIDED SIMULATION ANALYSIS FOR WEAR INVESTIGATION OF RAILWAY WHEEL RUNNING SURFACE
}

\author{
Pavol ŠŤASTNIAK ${ }^{1}$, LUKÁŠ SMETANKA ${ }^{2}$, Pawel DROZDZIEL ${ }^{3}$ \\ ${ }^{1}$ University of Žilina, Faculty of Mechanical Engineering, Department of Transport and Handling Machines, \\ Univerzitná 8215/1, 01026 Žilina, Slovak Republic, e-mail: pavol.stastniak@ fstroj.uniza.sk \\ ${ }^{2}$ University of Žilina, Faculty of Mechanical Engineering, Department of Design and Mechanical Elements, \\ Univerzitná 8215/1, 01026 Žilina, Slovak Republic, e-mail: lukas.smetanka@fstroj.uniza.sk \\ ${ }^{3}$ Lublin University of Technology, Faculty of Mechanical Engineering, Department of Transport, Combustion \\ Engines and Ecology, ul. Nadbystrzycka 36, 20-618 Lublin, Poland, e-mail: p.drozdziel@pollub.pl
}

Abstract

In railway applications wear prediction in the wheel-rail interface is a fundamental matter in order to study problems such as wheel lifespan and the evolution of vehicle dynamic characteristic with time. The change of the running surface of the railway wheels head has not only a great influence on the dynamic properties of the vehicle, but also a significant economical, safety and ecological impact in the process of the rail transport. One of the ways to predict these undesired situations are computer aided simulation analyzes. In this paper are presented results of wheel profile wear by Archard wear law, when the computational model of railway vehicle was driving in track by constant velocity. The vehicle was traveling along track where the rail profile was defined by standard (UIC 60 profile) with cant of 1:40, or the track profile really measured on the track, the profile S 91700_16 with the cant of 1:20. Simulations were realized by SIMPACK software.

Keywords: wear research, railway, wheel heads, computer simulation

\section{INTRODUCTION}

Wear belongs to the degradation processes, where material is lost from one or both surfaces of contact shapes of rigid bodies. Relative movement of the contact surfaces can directly lead to destroying of the component, or occurs disruption of the surface leading to the subsequent failure. Several factors influence the wear resistance, mostly: design solution, manufacturing process of component, operating conditions, material properties, thermal and thermal-chemical processing etc. The contact problem is characterized by large plastic deformation. On other side is wear caused by the application of the cyclic loading of the component, the nucleation of the crack and its spreading into the final state of the fracture of the material. This means that a worn fracture occurs after several thousand cycles, which correspond to the fatigue life of the loaded component [2, 6, 7].

During the operation of the railway transport, both wheel and rail wear occur, either due to normal operation or failure. With regard to the type of wear, the wear of rolling stock is based on the character of friction and also on the basis of cyclic fatigue. Over time the process of fatigue become separate scientific area named RCF (Rolling Contact Fatigue) [4].

The dynamic behaviour of rail vehicles on the track is significantly affected by the interaction between the wheel and the rail. In the depth of the examined issue is an understanding of the contact between the wheels and the rails. There are problems in this more in-depth study which stand alone are broad scientific areas. One of the most important areas with significant influence on geometry change and thus the change in contact conditions is undoubtedly the wear and related geometry changes of one part of the contact pair or both, such as the corrugation of the track and its irregularity, changes in friction and slip ratio or changes in vertical and longitudinal forces of the contact pair, etc. The impact of wear certainly affects also the acoustic and vibrational expression of the car on the rail, which, by increasing the negative side, devastates the environmental environment around the tracks [1].

\section{ARCHARD WEAR LAW IN SIMPACK SOFTWARE}

According to several literary sources, there are three main trends in the development of the wear, patterns from the middle to the end of the twentieth century and they are: based on empirical approach, based on a contact mechanics approach and based on a reflex mechanics approach. An irreplaceable and important factor in wear is friction. The hypothesis suggests:

$$
F_{F}=\mu . F_{N}[N]
$$


where $F_{F}$ is frictional force, $\mu$ is frictional coefficient, $F_{N}$ is applied normal force. This frictional equation is based on two basic assumptions, first is approach that the stress distribution is independent to normal load and second that the applied load is proportional to real contact area.

We knows more wear laws which were then development and modified, but all of them are based on basic theories from authors like Reye (1860), Tabor (1939), Holm (1946) a Archard (1953).

The supplement for wear determination is in SIMPACK software embedded to the module SIMPACK RAIL, it is therefore the determination of wear in the contact wheel-rail pair, where are the contact stresses solved by using the Kalker method named FASTSIM $[5,10]$. The developer motivated the application of supplement mainly to the issue of safety and maintenance, as is known, wheels and rails are subjected to wear and rolling contact fatigue (RCF) throughout their lifecycle, due the forces acting during frequent rail traffic. Considering that there are many different wear laws and RCF, the module has an open structure that makes it possible to implement the necessary changes to achieve the preferred type of wear. The SIMPACK software offers two different laws of wear and tear for simulation: Archard wear law and Krause/Poll wear law. Archard wear law is for the SIMPACK software based on the following equation:

$$
V=\frac{N \cdot \Delta s}{H} \cdot\left\{\begin{array}{cccc}
k_{1} & \text { if } p>f H & \text { (seizure) } \\
k_{2} & \text { if } p \leq f H \text { and } v_{s} \leq v_{1} & \text { (mild } 1) \\
k_{3} & \text { if } p \leq f H \text { and } v_{1}<v_{s} \leq v_{2} & \text { (severe) } \\
k_{4} & \text { if } p \leq f H \text { and } v_{2}<v_{s} & \text { (mild 2) }
\end{array}\right.
$$

where $\mathrm{V}$ - wear volume $\left[\mathrm{m}^{3}\right], \mathrm{N}$ - normal contact force $[\mathrm{N}], \Delta \mathrm{s}-$ sliding distance $[\mathrm{m}], \mathrm{H}-$ hardness of the softer material in contact pair [MPa], $\mathrm{k} 1-\mathrm{k} 4$ wear coefficients, (seizure, mild 1 , severe and mild 2) $[-], p-$ contact pressure $[\mathrm{MPa}], \mathrm{f}-$ hardness fraction $\mathrm{H}$ over which destruction occurs (seizure), $\mathrm{v}_{\mathrm{s}}$ - sliding (relative) velocity $[\mathrm{m} / \mathrm{s}], \mathrm{v}_{1,2}$ - boundary velocities, in which the wear coefficients are changing from mild 1 to severe and back to mild 2 [m/s].

The sliding distance is calculated from actual output step. The normal force, pressure and sliding (relative) velocity are selected from wheel-rail contact elements. The typical values for wear coefficients are used in literature like: $\mathrm{k}_{1}=300-$ $400 \times 10^{-4}, \mathrm{k}_{2} \approx \mathrm{k}_{4}=1-10 \times 10^{-4}$ and $\mathrm{k}_{3}=30-40$ $\mathrm{x} 10^{-4}$.

\section{PREPARATION OF SIMULATION}

For the simulation of wear was necessary create the most accurate model of the vehicle so that the simulation showed the best possible match with the actual vehicle on the real track. The SIMPACK software has been selected as a suitable solution for this simulation, which enables us to achieve the desired behaviour of the vehicle with its characteristic features. The software allows for a quick and comfortable assembly of the MBS (Multibody Simulation) model of a rail vehicle that meets the wheel-rail contact specifications.

\subsection{Parameters of vehicle}

The computational model is characterized by vehicle parameters, geometric and weight parameters, elastic parameters of springs and dampers, and the like. Additionally, they are the parameters of the contact between wheel and rail and the track parameters [3, 8, 9]. This article presents results for one vehicle model (Fig. 1) Model A.

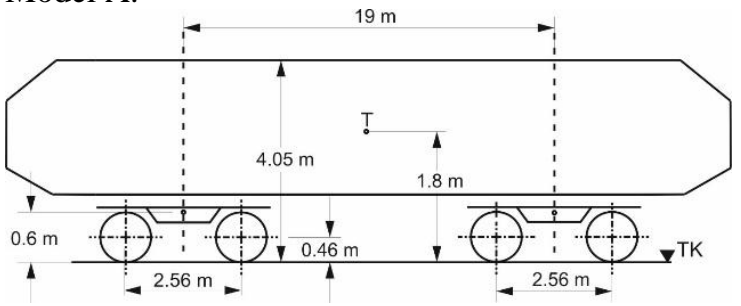

Fig. 1. Schematic sketch of the vehicle (Model A)

The weight parameters, elastic parameters of springs and dampers and geometrical parameters of the vehicle are described in following tables.

Table 1. Weight parameters

\begin{tabular}{|r|r|r|r|r|}
\hline & $\mathrm{m}[\mathrm{t}]$ & $\mathrm{I}_{\mathrm{xx}}\left[\mathrm{kg} \cdot \mathrm{m}^{2}\right]$ & $\mathrm{I}_{\mathrm{yy}}\left[\mathrm{kg} \cdot \mathrm{m}^{2}\right]$ & $\mathrm{I}_{z z}\left[\mathrm{~kg} \cdot \mathrm{m}^{2}\right]$ \\
\hline Wheelset & 0.91 & 478.69 & 79.27 & 478.69 \\
\hline Bogie frame & 1.15 & 1045.47 & 1127.26 & 2094.20 \\
\hline Vehicle casing & 22.23 & 39607.40 & 1303000.00 & 1294000.00 \\
\hline
\end{tabular}

Table 2 Elastic parameters of springs and dampers

\begin{tabular}{|r|r|r|r|}
\hline Springing & \multicolumn{1}{c|}{$\mathrm{c}_{\mathrm{x}}\left[\mathrm{N} \cdot \mathrm{m}^{-1}\right]$} & \multicolumn{1}{c|}{$\mathrm{c}_{\mathrm{y}}\left[\mathrm{N} \cdot \mathrm{m}^{-1}\right]$} & \multicolumn{1}{c|}{$\mathrm{c}_{\mathrm{z}}\left[\mathrm{N} \cdot \mathrm{m}^{-1}\right]$} \\
\hline Primary & 608025.44 & 608025.44 & 695678.15 \\
\hline Secondary & 468148.52 & 468148.52 & 604452.96 \\
\hline Damping & $\mathrm{d}_{\mathrm{x}}\left[\mathrm{N} . \mathrm{s} . \mathrm{m}^{-1}\right]$ & $\mathrm{d}_{\mathrm{y}}\left[\mathrm{N} . \mathrm{s} . \mathrm{m}^{-1}\right]$ & $\mathrm{d}_{\mathrm{z}}\left[\mathrm{N} . \mathrm{s} . \mathrm{m}^{-1}\right]$ \\
\hline Primary & 5000 & 5000 & 17700 \\
\hline Secondary & 100 & 100 & 34340 \\
\hline
\end{tabular}

Table 3. Geometrical parameters of vehicle

\begin{tabular}{|l|r|}
\hline \multicolumn{1}{|c|}{ Parameter } & \multicolumn{1}{|c|}{ Value } \\
\hline $\begin{array}{l}\text { The trans verse distance of activities of primary } \\
\text { springing and damping }\end{array}$ & $2000 \mathrm{~mm}$ \\
\hline $\begin{array}{l}\text { The trans verse distance of activities of secondary } \\
\text { springing and damping }\end{array}$ & $2000 \mathrm{~mm}$ \\
\hline The distance of rotary pin of bogie & $19000 \mathrm{~mm}$ \\
\hline The whe elbase of bogies & $2560 \mathrm{~mm}$ \\
\hline Nominal wheel diame ter & $920 \mathrm{~mm}$ \\
\hline Height of center of gravity for whe elset above TK & $460 \mathrm{~mm}$ \\
\hline Height of center of gravity for bogie frame above TK & $600 \mathrm{~mm}$ \\
\hline Height of center of gravity for vehicle casing above TK & $1800 \mathrm{~mm}$ \\
\hline Height of the primary springing above TK & $345 \mathrm{~mm}$ \\
\hline Height of secondary pringing above TK & $390 \mathrm{~mm}$ \\
\hline Track gauge & $1435 \mathrm{~mm}$ \\
\hline Frictional coefficient & 0.1 \\
\hline
\end{tabular}

\subsection{Parameters of vehicle}

The model track consists from the straight sections, clothoid transitions and superelevations segments in the curves of the track. The Fig. 2 
shows the horizontal track profile, which were by wear simulation used with aim to determine the wear of the vehicle on the track. The length of the model track is $400 \mathrm{~km}$ and from picture is clearly that the profile is very diverse.

The track consists from 24 right and 24 left curves of track, the vehicle runs in straight track overall $366 \mathrm{~km}$ and $44 \mathrm{~km}$ in curves of track. The superelevations of the outer ribbon in the curves of track are for each curve of another value. The model track it is not considered like ideally horizontally and vertically straight, in the simulation is considered lateral and vertical irregularities on track too. The irregularities cause the excitations of dynamics system by driving the vehicle on the track and are mostly stochastic.

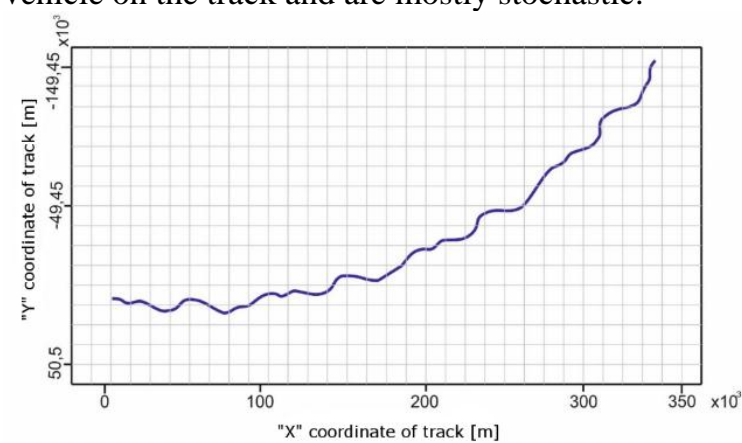

Fig. 2. Horizontal track profile

The Fig. 3 shows the rail profiles which were used by wear simulations. All the analyses are comply to condition, that the vehicle was traveling along track where the rail profile was defined by standard (UIC 60 profile) with cant of 1:40, or the track profile really measured on the track, the profile S 91700_16 with the cant of 1:20.
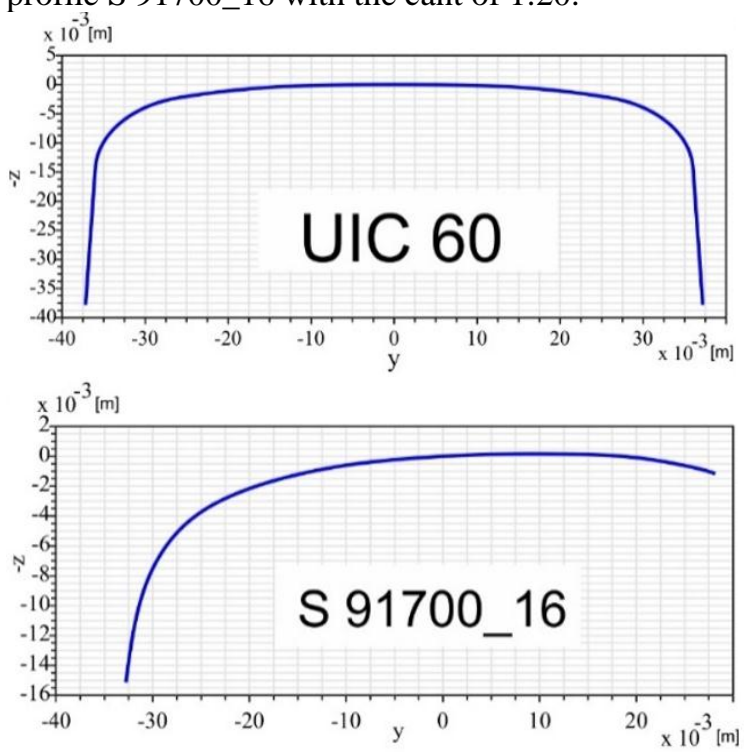

Fig. 3. Rail profiles

\section{PREPARATION OF SIMULATION}

The wear simulation process was chosen for the different distance travelled along the track by the following scheme.
The data flow from Start to Finish can be controlled by programmed cycle or the user can control it manually. The programmed cycle has a significant contribution to simulation mainly in terms of time but has a huge disadvantage in the necessity of building such a cycle. For this reason, we have managed this data flow described on display scheme (Fig.4) by entering the necessary condition manually.

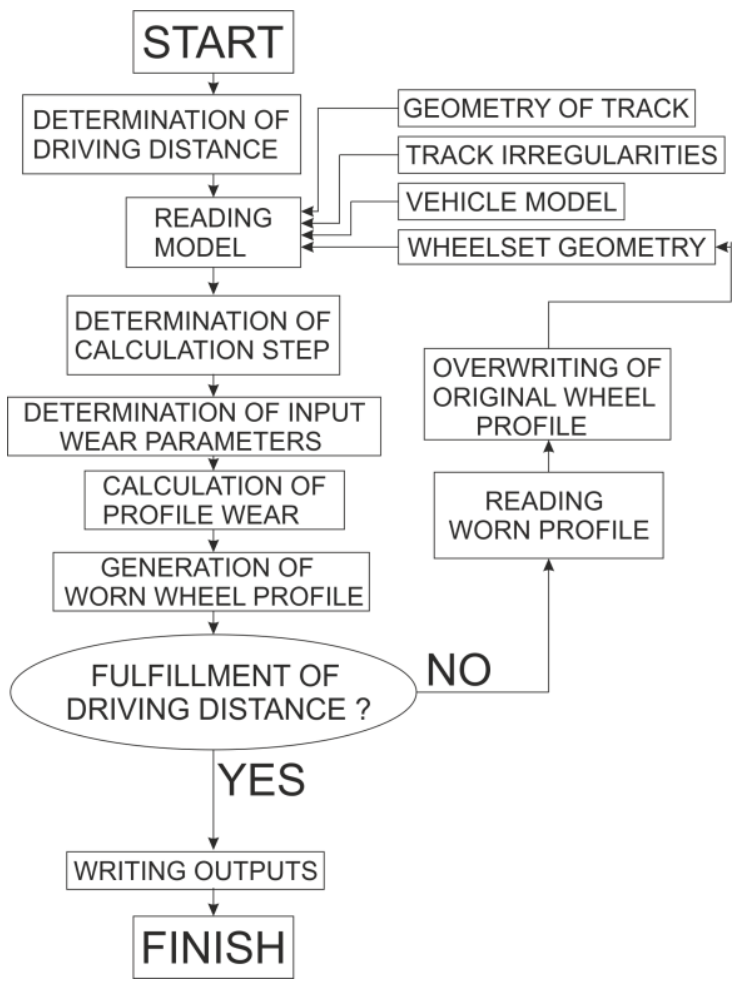

Fig. 4. Wear simulation scheme

Table 4. Wear coefficients used in analysis

\begin{tabular}{|c|c|c|}
\hline Wear & \multicolumn{2}{|c|}{ Archard law } \\
\hline & theoretical & modified \\
\hline C mild 1 & 0.0005 & 0.0000833 \\
\hline C mild 2 & 0.0005 & 0.0000833 \\
\hline C severe & 0.0035 & 0.000583 \\
\hline C seizure & 0.035 & 0.005833 \\
\hline Distance factor & 20 & 20 \\
\hline
\end{tabular}

The simulations were performed in two variants, by driving the vehicle Model A on the track with rail profile UIC 60 or rail profile S 91700_16. The vehicle velocity was constantly set at $30 \mathrm{~m} . \mathrm{s}^{-1}$. The wear coefficients for Archard wear law was chosen from the range of values displayed in the Table.4. It was performed total of 30 analyses, 15 for one rail profile and 15 for the second rail profile. The distance overtaken by the vehicle in one analysis

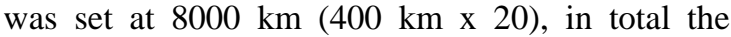
vehicle was travelled $120000 \mathrm{~km}(8000 \mathrm{~km}$ x 15 analyses). The computational time was for one analysis around 59 hours CPU time. The results were processed after each fifth analysis, that is after departing $40000 \mathrm{~km}, 80000 \mathrm{~km}$ and $120000 \mathrm{~km}$. 


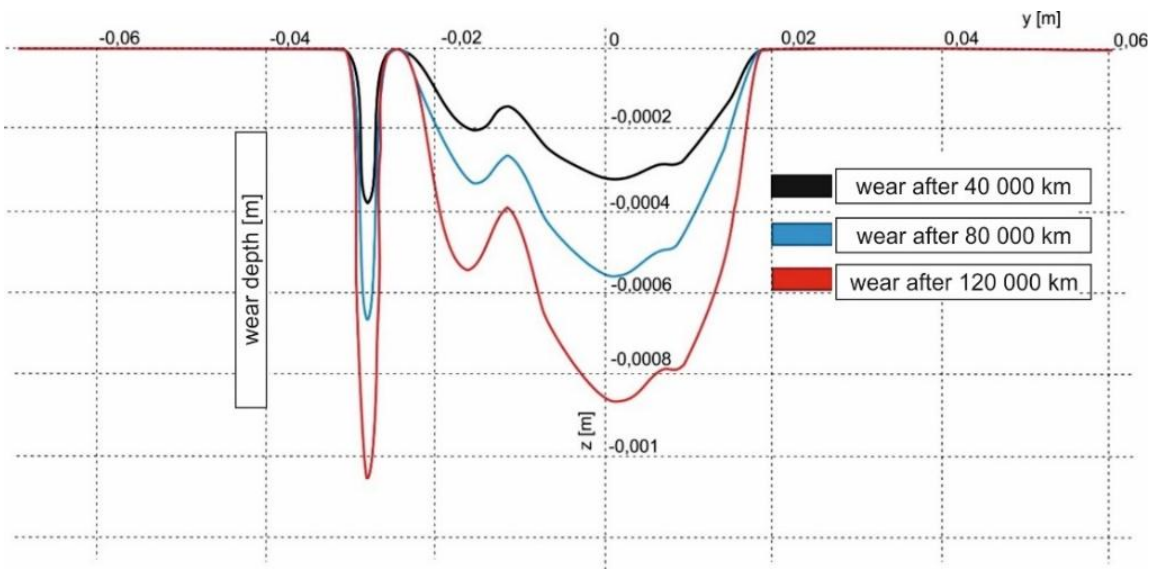

Fig. 5. Wear depth for Model A by driving on the UIC 60 rail profile

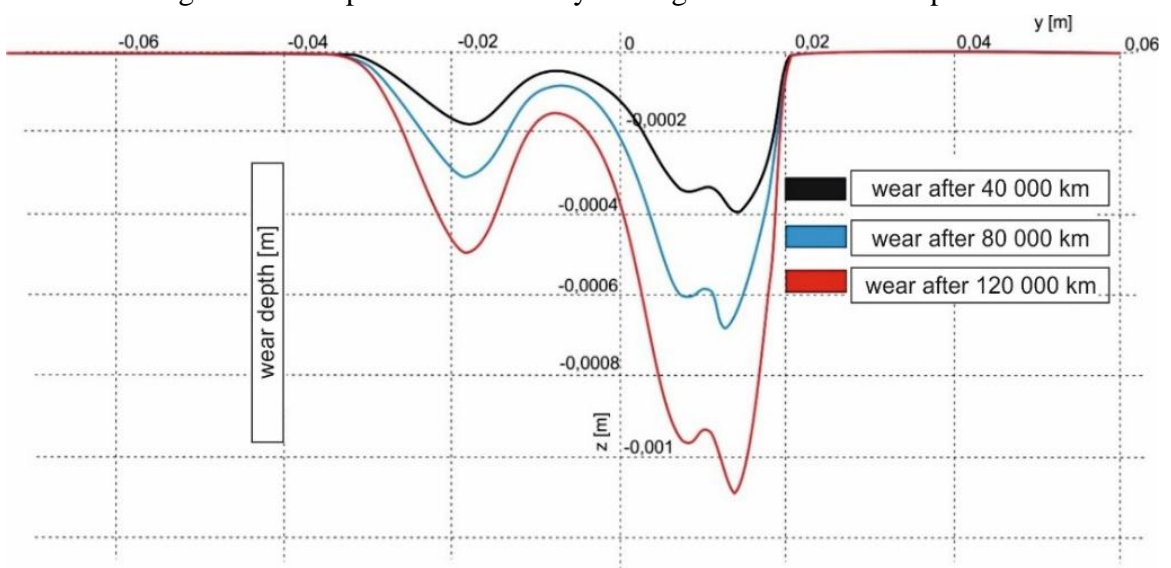

Fig. 6. Wear depth for Model A by driving on the S 91700_16 rail profile

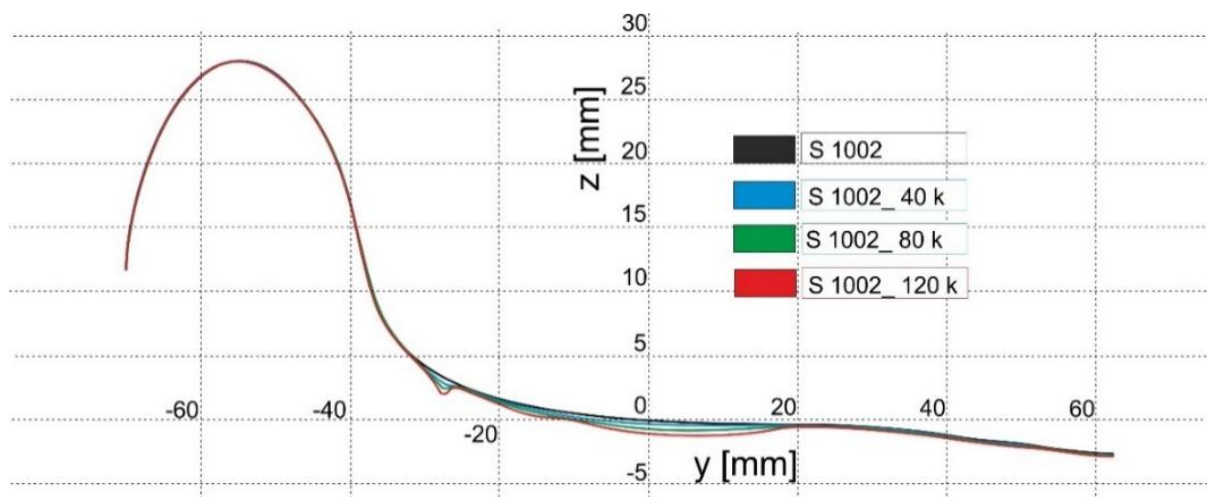

Fig. 7. Worn profiles by driving on the UIC 60 rail profile

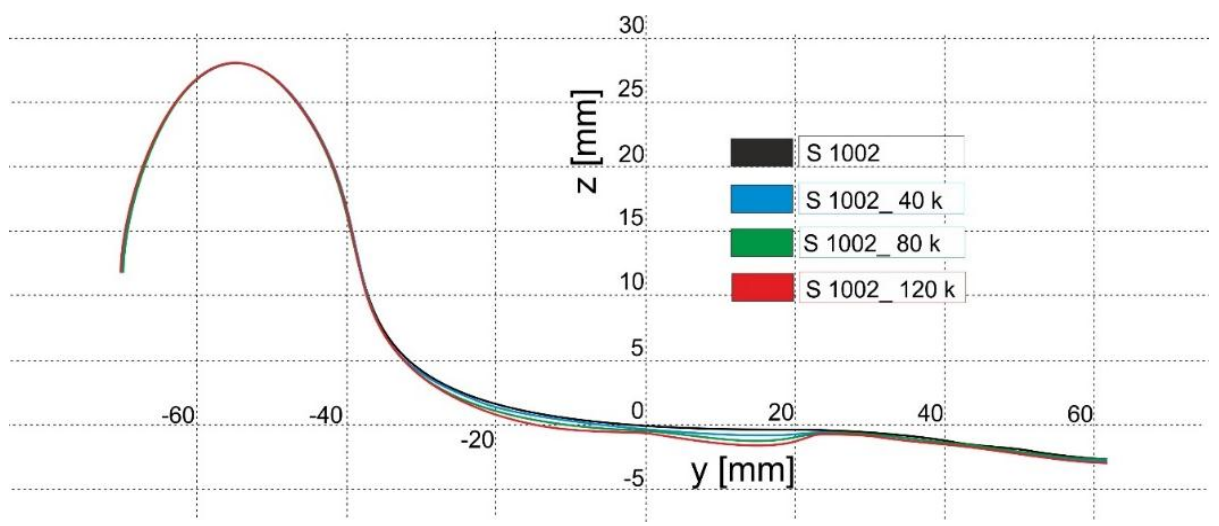

Fig. 8. Worn profiles by driving on the S 91700_16 rail profile 
On Fig. 5 and Fig. 6 are displayed the curves of wear depth for two rail variants (UIC 60 and $\mathrm{S}$ 91700_16). The black curve represents wear depth after departing $40000 \mathrm{~km}$, blue curve represents wear depth after departing $80000 \mathrm{~km}$ and red curve represents wear depth after departing $120000 \mathrm{~km}$. The wear depth value was subtracted during processing from theoretical standardized profile S1002.

On Fig. 7 and Fig. 8 are displayed the curves of worn profiles by departing $40000 \mathrm{~km}$ (blue curve), $80000 \mathrm{~km}$ (green curve) and $120000 \mathrm{~km}$ (red curve) compared to the original theoretical profile $\mathrm{S}$ 1002 (black curve). Fig 7 represents worn profiles where the simulated vehicle Model A driving on the track with UIC 60 rail profile, with rail cant 1:40. Fig 8 represents worn profiles where the simulated vehicle Model A driving on the track with measured S 91700_16 rail profile, with rail cant 1:20. In Fig. 7 we can notice near to wheel flange the irregularity of worn profile, which would not be possible in real traffic. This irregularity presents in each displayed curves (after $40000 \mathrm{~km}$, after 80 $000 \mathrm{~km}$ and after $120000 \mathrm{~km}$ ) we assign to numerical calculation error. During simulation occurs the change the transverse position of wheelset in the track. For this reason changes the contact area and contact stress has a higher value. By the calculating with Archard wear law (Eq. 2) occurs multiplication with higher value of contact stress and arises the irregularity which would not be possible in real traffic. Another factor of irregularity is the change of sliding velocity by driving in the curves of track.

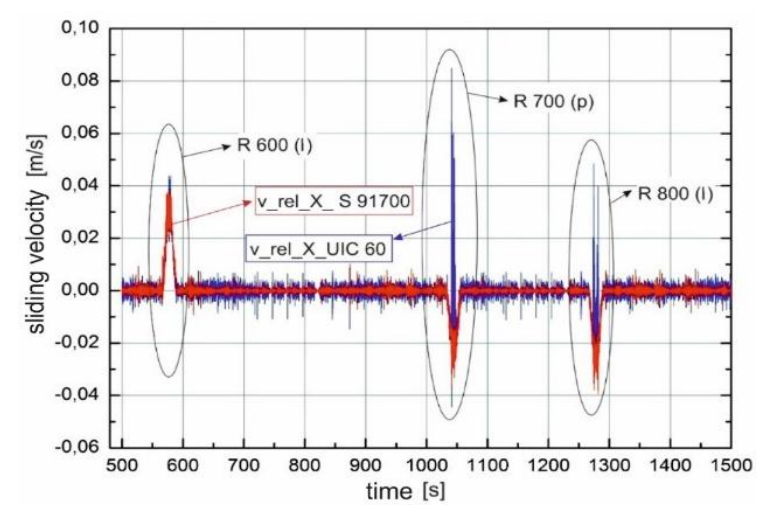

Fig. 9. Longitudinal sliding velocities by driving in the curves of track

In Fig. 9 we can notice the change of sliding velocity by driving in the curves of track where is obvious that higher values of the longitudinal sliding velocity are present in the peak by driving at theoretical UIC 60 rail profile. For the curve of track with radius $\mathrm{R} 700$ (p) is the peak of longitudinal sliding velocity higher than $0.8 \mathrm{~m} . \mathrm{s}^{-1}$, which is boundary value for the change wear coefficient from mild to severe. For this reason, are variables in that area multiplied with 10-times value. This also has a significant impact on the numerical error that has occurred.

This numerical error is not occurred in Fig. 8 by driving on the track with measured S 91700_16 rail profile.

\section{CONCLUSION}

This article is aimed to the simulation model of railway wheel wear. The motivation to create such a model was the fact that the impact of wear affects the geometrical characteristics of the contact pair, the change of force and slip ratios in contact area, extends to the acoustic and vibration driving behaviour which by rising the negative side disrupts the environment surrounding the tracks. In the article are presented the results of wear simulations for the vehicle Model A, which travelled at the constant velocity along the track. It is important to note, that in the simulations the impact of the starting and braking of the railway vehicle is neglected.

With this research deals other publications too [11-19].

\section{SOURCE OF FUNDING}

This paper was created in accordance to the processing of the project "Development of two types of freight wagons with bogies for nonstandard wheelbase or track wheelset, complying with the criteria for interoperability, Environmental Issues, safety and reliability“, ITMS Code 26220220070 based on the support of Research and Development Operational Program co-financed from EU sources.

This work was also created with the financial support of the Agency for Support of Research and Development of the Ministry of Education, Science, Research and Sport of the Slovak Republic VEGA 1/5058/18: Research of the interaction of a braked railway wheelset and track in simulated operational conditions of a vehicle running in a track on the test bench.

\section{REFERENCES}

1. Argatov II, Fadin YA. Mathematical modeling of the periodic wear process in elastic contact between two bodies. Journal of Friction and Wear 2008; 29(2): 8185. https://doi.org/10.3103/S1068366608020013.

2. Barbinta CI, Ulianov C, Franklin F, Cretu S. Wheelrail contact modelling and analysis, considering profiles types and lateral displacement. Transport Research Arena: 5th Conference: Transport Solutions from Research to Deployment 2014. France: Paris. Accession Number: 01540797.

3. Dižo J. Steišunas S, Blatnický M. Vibration analysis of a coach with the wheel-flat due to suspension parameters changes. Procedia Engineering 2017; 192: 107-112.

https://doi.org/10.1016/j.proeng.2017.06.019. 
4. Enblom R., Berg M. Simulation of railway wheel profile development due to wear - influence of disc braking and contact enviroment. Wear 2005; 258(7): 1055-1063. https://doi.org/10.1016/j.wear.2004.03.055.

5. Gerlici J, Kravchenko K, Nozhenko O, Lack T, Gorgunov M, Kostyukevich A. Experimental rigs for wheel/rail contact research. Manufacturing technology. 2016; 16(5): 909-916.

6. Gerlici J, Gorbunov M, Nozhenko O, Pistek V, Kara S, Lack T, Kravchenko K. About creation of bogie of the freight car. Communications - Scientific letters of the University of Zilina 2017; 19(2): 29-35.

7. Hauser V, Nozhenko O, Kravchenko K, Loulová M, Gerlici J, Lack T. Impact of three axle boxes bogie to the tram behavior when passing curved track. Procedia Engineering 2017; 192: 295-300. https://doi.org/10.1016/j.proeng.2017.06.051.

8. Kohár R, Hrček S. Dynamic analysis of rolling bearings with elastic cage. Lecture Notes in Mechanical Engineering 2014; 16: 249-254. https://doi.org/10.1007/978-3-319-05203-8_35.

9. Kohár R, Hrček S. Dynamic analysis of a rolling bearing cage with respect to the elastic properties of the cage for the axial and radial load cases. Communications - Scientific letters of the University of Zilina 2014; 16(3a): 74-81.

10. Lack T, Gerlici J. Railway wheel and rail roughness analysis. Communications - Scientific letters of the University of Zilina 2009; 11(2): 41-48.

11. Niziński S, Wierzbicki S. Zintegrowany system informatyczny sterowania pojazdów. Diagnostyka. 2004; 30:47-52. Polish.

12. Pombo J, Ambrósio J, Pereira M, Lewis R, DwyerJoyce R, Ariaudo C, Kuka N. Development of a wear prediction tool for steel railway wheels using three alternative wear functions. Wear 2011; 271(1-2): 238-245. https://doi.org/10.1016/j.wear.2010.10.072

13. Pelagić Z, Nágel' $M$, Žmindák M, Riecky D. Wear simulation modeling by using the finite element method. Manufacturing technology: Journal for science, research and production 2015; 15(2): 191195.

14. SakhnoV, Gerlici J, Poliakov V, Kravchenko A, Omelnitcky O, Lack T. Road train motion stability in BRT system. XXIII Polish-Slovak scientific conference on machine modelling and simulations. ISSN 2261-236X. London: EDP Sciences, 2019. https://doi.org/10.1051/matecconf/201925403007

15. Sawczuk W. Evaluation of the wear of friction pads railway disc brake using selected pont parameters of vibrations signal generated by the disc brake. Diagnostyka 2014; 15(3): 33-38.

16. SIMPACK A.G. Documentation to the program system SIMPACK, 2014.

17. Wierzbicki S. Diagnosing microprocessor controlled systems. Polska Akademia Nauk, Teka Komisji Motoryzacji i Energetyki Rolnictwa, Tom VI, Lublin, 2006, p. 183-188.

18. Zhao X, Zhang P, Wen Z. On the coupling of the vertical, lateral and longitudinal wheel-rail interactions at high frequencies and the resulting irregular wear. 11th International Conference on Contact Mechanics and Wear of Rail/Wheel Systems.

Delft, Netherlands. Wear 2018, 430: 317-326. https://doi.org/10.1016/j.wear.2019.05.017

19. Žmindák M, Mikušík J, Klimko J. Dynamic rolling contact stress analysis of cylindrical roller bearings using FEM. 10th Biennial International Conference on Vibration Problems. Prague, Czech Republic. Vibration problems, ICOVP 2011, 186-191.
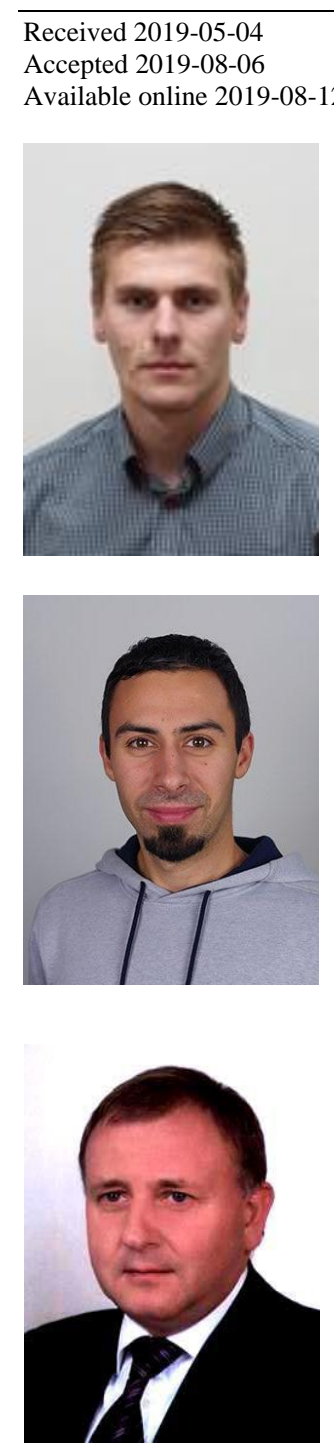

Ing. Pavol ŠŤASTNIAK, PhD. received B.Sc., M.Sc. and $\mathrm{PhD}$. degrees in Mechanical Engineering from University of Žilina, respectively. $\mathrm{He}$ is currently working as researcher at the Faculty of Mechanical Engineering, University of Žilina and his research interest mainly focuses on creation of railway vehicles and analysing dynamic and structural properties of railway vehicles development.

Ing. Lukáš SMETANKA, PhD. received B.Sc., M.Sc. and $\mathrm{PhD}$. degrees in Mechanical Engineering from University of Žilina, respectively. $\mathrm{He}$ is currently working as researcher at the Faculty of Mechanical Engineering, University of Žilina and his research interest mainly focuses on creation of MBS models and analysing dynamic structural properties of transport and handling machines.

Dr. hab. inż Pawel DROŹDZIEL, prof. PL works at the Institute of Transport, Combustion Engines and Ecology of Faculty of Mechanical Engineering of Lublin University of Technology, ViceRector of this university. Prof. Droździel focuses his research activities mainly on solving problems in the field of tribology, durability and safety technical systems. 